\title{
La construcción del desarrollo desde abajo*
}

\begin{abstract}
Síntesis:
Este proyecto parte del interés por realizar un proceso comunicativo en donde las redes sociales se puedan articular entre los miembros de las Juntas Comunales de los municipios de Agua de Dios y Girardot y otros sujetos individuales y colectivos, para construir un capital social capaz de contribuir al desarrollo de este sector de Cundinamarca. Este artículo está centrado en la presentación de los resultados finales de la investigación.
\end{abstract}

Palabras clave: participación, lo público, comunicación y desarrollo, redes sociales, ciudadanía, planeación participativa, Juntas Comunales.

\section{Synthesis:}

This project started from the interest to accomplish a communication process in which the social network can be articulated between members of the Communal Committee of Agua de Dios and Girardot and other individual and collective subjects, in order to construct a social capital capable to contribute

to the development of this Cundinamarca's sector. This article is centered on the presentation of the investigation final results.

Key Words: participation, the public, communication and development, social networks, citizenship, participatory planning, Juntas Comunales.
César Rocha**

e-mail: crocha@uniminuto.edu

Elssy Moreno

e-mail: elyamope@yahoo.es

Ibeth Molina

e-mail: ibethmol@gmail.com

Gonzalo Ortiz

e-mail: goortiz@uniminuto.edu

Docentes e investigadores de la

Facultad de Ciencias de la Comunicación de Uniminuto

Fecha de recepción:30-05-08

Fecha de aprobación: 21-06-08

"...Lo que se advierte ampliamente en la Colombia de los noventa es la pluralidad de colectividades o sociabilidades fragmentadas, con fuertes

identidades en su interior, surgidas de lo vivido en común y regidas por lógicas y sentidos particulares que no se enmarcan en el modelo republicano ciudadano que simula un solo centro de poder, dirección y control, y un espacio público homogéneo y sin fisuras".

María Teresa Uribe de $\mathbf{H}$.

*El proyecto se titula "La reconstrucción del capital social a partir de la constitución de redes de cooperación colectiva en una provincia de Cundinamarca”. Fue seleccionado por Colciencias (Convocatoria 331 de 2006, Cambio cultural, instituciones y educación para el desarrollo) y recibe su apoyo financiero. Contó con la participación de estudiantes de la sede Bogotá y docentes y estudiantes de la regional Girardot de la Facultad de Ciencias de la Comunicación de la Corporación Universitaria Minuto de Dios.

${ }^{* *}$ Director del programa de Comunicación Social-Periodismo de la Facultad de Ciencias de la Comunicación de Uniminuto y director de la investigación. 


\section{Introducción}

Esta es una alternativa para construir/fortalecer un tejido social que sustente la convivencia y la comunicación en la Provincia del Alto Magdalena, ubicada en el departamento de Cundinamarca, que asume el desarrollo como la posibilidad de hacerse partícipes de un proyecto colectivo, integral y sostenible de interaprendizaje. Desde este lugar, el desarrollo parte de los propios intereses de los involucrados, pero se relaciona con los conflictos territoriales existentes, para ir poco a poco constituyendo sujetos de desarrollo en la medida en que se interlocute entre unos y otros.

Para lograrlo, se empleó una metodología participativa en cuatro fases. En la primera fase se reconocieron las diferentes percepciones, intereses y lógicas de vida de los miembros de las Juntas de Acción Comunal frente al desarrollo social, a partir de unas entrevistas estructuradas a los directivos de cuarenta Juntas de Acción Comunal de Agua de Dios y Girardot. En la segunda fase, se diagnosticó la dinámica organizativa de manera participativa, lo mismo que las relaciones en el plano de lo público, es decir, reconocer las fortalezas y debilidades de estas instituciones sociales como partícipes del desarrollo territorial a partir de la realización de mapas de cartografía social y redes sociales.

En la tercera fase se buscó que los miembros de estos grupos identifiquen los conflictos territoriales en los cuales se han visto más involucrados y que consideran de mayor relevancia en su municipio o provincia, y que reflexionan conjuntamente acerca de los mismos, a través de diversos escenarios de discusión y problematización.

Finalmente, en la cuarta fase se dio paso a la reflexión en torno a la planeación participativa y al diseño de las redes comunicativas. A continuación presentamos los resultados de la investigación, desde una perspectiva crítica y propositiva.

\section{La participación en lo público}

Desde hace más de una década, específicamente desde la promulgación de la Carta Magna de 1991, la participación política se convirtió en uno de los centros del debate democrático, y su diseño dentro de la Constitución -a través de los llamados "mecanismos" de participación ciudadanos- en principio, se consideró como un acierto y luego de su puesta en marcha, la opinión ha ido cambiando hacia una percepción más bien negativa. Hoy existe un gran debate al respecto.

Pero, ¿qué entendemos por participación? Si miramos la Gran Enciclopedia Espasa, dice que participación es: 1) "tener uno parte en una cosa o tocarle algo de ella; 2) compartir, tener las mismas opiniones o ideas que otra persona; y 3) dar parte, comunicar" "1. Veámoslo por partes: no creemos que la participación implique tener las mismas ideas de otros o informarle algunos sucesos a otros. La participación implicaría entonces hacer parte de una institución (privada o pública), compartir con otros las ideas y las percepciones y comunicarse con ellos.

La participación es, pues, un elemento clave para la vida en cualquier sociedad. No todos los individuos de una sociedad participan porque no todos se comunican, socializan sus opiniones, tienen en cuenta las de otros o hacen parte de instituciones. Sin embargo, también podemos decir que es muy posible que buena parte de la sociedad cumpla con alguno de estos

${ }^{1}$ ESPASA Calpe, Gran Enciclopedia Espasa, №. 15, Colombia, 2005, pág. 9050 . 
4 Irth 
individuos con el fin de intervenir en la esfera pública a partir del bien o interés común. La participación ciudadana opera también en la esfera pública pero desde los intereses privados (territoriales, corporativos o gremiales). La participación social tiene que ver con el agrupamiento de personas con intereses similares que buscan alguna reivindicación. Y la participación comunitaria alude igualmente a un agrupamiento social pero su objetivo es la búsqueda de la mejoría en las condiciones de vida². Las dos últimas operan en la esfera privada.

Si aceptamos lo dicho por Cunill, para lograr la participación política tendríamos que contar con unos ciudadanos diferentes a los que tenemos. Ya vimos que para una sociedad es una práctica compleja, y especialmente en este caso porque de plano los individuos tendrían que buscar el interés común. Hemos visto como en general cada actor social busca alcanzar su interés.

En nuestra opinión, participar con otros en una acción colectiva es una opción bien complicada. Implica reconocer el interés del otro y validarlo, tener la capacidad de generar proyectos colectivos, construir un tejido social medianamente fuerte, y básicamente, confiar en el "otro" y que ese "otro" confíe en "uno". Si hablamos de participación política no solamente tenemos que asumir los elementos anteriores, sino que además se deberá construir un fin público. Es decir cuando a la participación se le da el apellido

${ }^{2}$ La cita sobre lo dicho por Nuria Cunill se encuentra en:

VELÁSQUEZ, Fabio y GONZÁLEZ, Esperanza, ¿Qué ha pasado con la participación ciudadana en Colombia?, Bogotá, Fundación Corona, Fundación Social, Foro Nacional por Colombia, Banco Mundial, CIDER, Universidad de Los Andes, Corporación Región, Corporación Viva la Ciudadanía, Corporación Transparencia por Colombia, 2003, pág. 60.

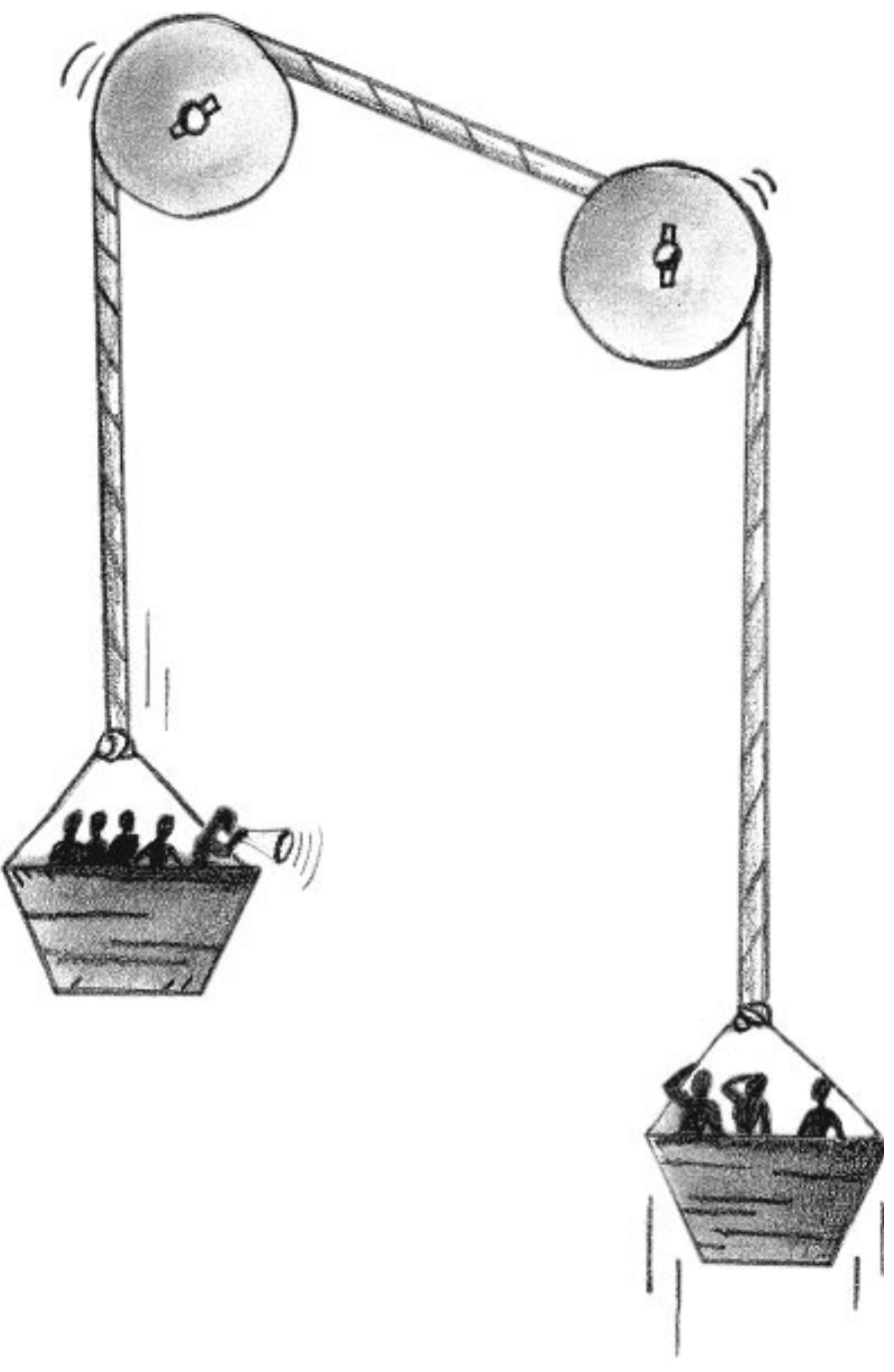




\section{Desarrollo}

"público" se carga de sentido porque ello implica el establecimiento de un propósito, de una ruta: la vía de lo público.

Al contrario de lo que piensa Cunill, en este proyecto asumimos que toda participación colectiva debiera ser política. Los intereses de los individuos o de los grupos pueden originarse en la esfera privada, de hecho en la mayoría de las ocasiones así es, pero se deben reconfigurar en la esfera pública. Lo que ocurre actualmente es que la participación se da en lo privado, así se trate de organizaciones altruistas como las Juntas Comunales. Lo público no existe o por lo menos no es muy visible.

Entonces ¿cuál es el fin de la participación? El reto consiste en construir lo público. Las Juntas Comunales han tenido muchas dificultades para involucrarse en dinámicas de participación. Les ha costado construir el "nosotros para lo público" porque ha pesado mucho el "yo y el nosotros para lo privado". Sin embargo, desde el "yo", que sería la representación, se han alcanzado grandes metas. El país se ha gestionado desde las Juntas y esos liderazgos han reemplazado al Estado en muchas ocasiones. Los bienes públicos siempre han estado presentes en los planes de trabajo de las Juntas, pero para satisfacer el interés privado. Desde abajo también lo público se ha privatizado.

\section{Dificultades y retos actuales de las Juntas Comunales}

Las Juntas Comunales se convirtieron por mucho tiempo, en uno de los

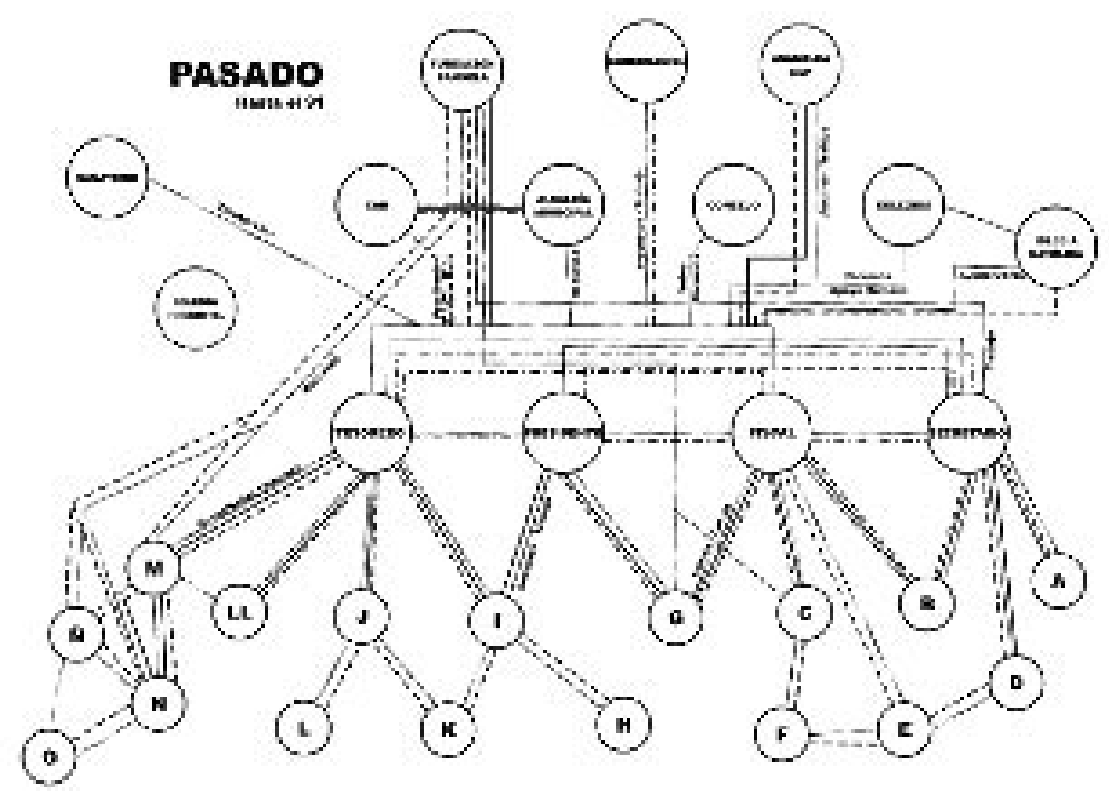




\section{Convenciones:}

Cooperacion $\ldots \ldots \ldots \ldots \ldots \ldots \ldots$
Confiarza
Canflicto
Poćer

Red No. 2. Presente de las JAC de Agua de Dios

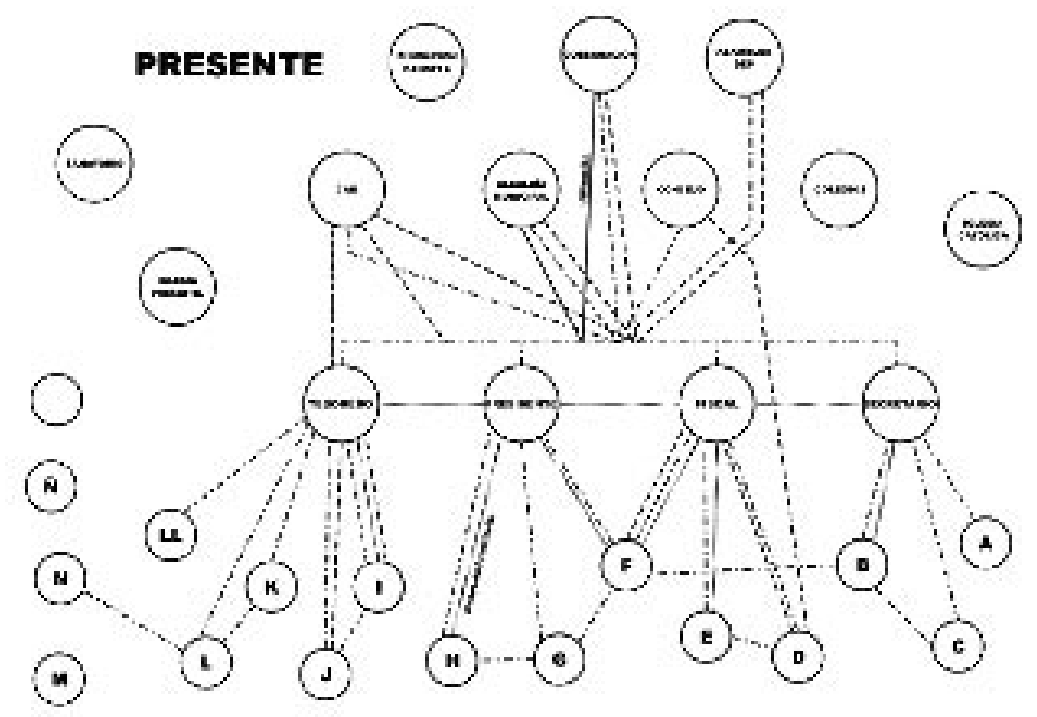

era básicamente de todos los habitantes. Claro que los primeros siguieron abrogándose el derecho de representar a los demás. Adicionalmente, los directivos comunales, en la medida en que el efecto de su trabajo era menor, le otorgaban mayor responsabilidad a las administraciones municipales. Y estas últimas, no dejan de criticar la desarticulación comunal y cómo esta situación no permite la viabilidad de los proyectos de desarrollo.

En últimas, lo que se nota en este ambiente de zozobra es una redistribución de la culpa frente a la ineficacia de la participación que trae como consecuencia la disminución de los proyectos colectivos, la pérdida de legitimidad de las Juntas y la dependencia de las administraciones de los municipios.

Si lo que buscamos es la reconstrucción del capital social entonces tendríamos que volver a construir socialmente a la "comunidad" desde la esfera pública, pero contando con los intereses individuales o particulares.

Es decir, eso "comunal", que tenía que ver con intereses particulares y en ocasiones públicos, podrían reconfigurarse en una esfera incluyente: la pública. Lo público actualmente

A lo largo del proceso descrito, la responsabilidad se fue delegando de unos a otros. Los habitantes de los municipios después de confiar ciegamente en sus representantes comenzaron a dejar de cooperar, asumiendo que la responsabilidad de lo "comunal" le correspondía a los directivos comunales. En este nuevo plano, lo "comunal" se lograba por la acción de los representantes. Pero éstos -los directivos- suponían que sólo alcanzarían los propósitos "comunales" a través de una acción conjunta, por tanto la responsabilidad no se construye con intereses comunes únicamente, sino también de intereses y expectativas particulares.

Las Juntas Comunales cuentan con destrezas y capacidades para "resolver problemas" casi de cualquier tipo. Las prácticas y habilidades que los comunales han adquirido a través del tiempo pueden emplearse en la gestión de buena parte de los asuntos públicos, dado que el quehacer comunal no distingue bienes públicos, sino por el contrario, los acoge a todos. 
Es muy posible que al asumir lo público poco a poco se vayan subsanando los grandes retos que tienen hoy las Juntas: Primero, apostarle a la construcción de comunidad, que no es una tarea nada fácil. Segundo, fortalecer las relaciones de confianza entre los directivos de las JAC y entre éstos y los dignatarios en general. Tercero, la construcción colectiva de un proyecto que oriente y redefina el rol de las JAC en el municipio. Cuarto, definir estrategias que dinamicen las relaciones de poder, propendiendo por escenarios y reglas de juego más equitativos. Quinto, hacerse co-responsables de los conflictos territoriales. Y sexto, fortalecer los procesos de empoderamiento y auto-organización.

\section{La planeación participativa en el desarrollo}

Los directivos de las Juntas Comunales se han convertido en "ciudadanos del desorden". Es decir, ciudadanos que han hecho ciudad, región y país, gracias al clientelismo, un tipo de gestión que por un buen tiempo les dio resultado. Ese "desorden" es un "orden" en el cual la estrategia fundamental era la consecución de los recursos por medio del intercambio de éstos (materiales, simbólicos, etc.) entre los representantes de la comunidad y sus representados y entre los primeros y la clase política. En este "desorden" ganaron los partidos políticos, los líderes comunales y los habitantes de los municipios, pero al tiempo perdió el país porque se legitimó la corrupción, se perpetuaron las élites en el poder, se despilfarró el presupuesto de la nación, de los departamentos y de los demás municipios, y se acentuó la cultura de la ilegalidad, según la cual, "el fin justifica los medios".

En Colombia siempre ha existido legalmente un Estado, pero éste no siempre se ha hecho visible para los grupos sociales. Es más, tal vez por esa razón no sólo las Juntas Comunales, sino otros actores sociales se

\section{Desarrollo}

convierten en Estado en diversas zonas del país. Las Juntas fueron Estado, pero luego, al formalizarse, se convirtieron en un instrumento del Estado. Cuando fueron Estado, ganaron reconocimiento por su eficacia, y cuando no lo fueron, perdieron por la falta de eficacia de los gobiernos de turno.

Pues bien, hoy una de las formas de alcanzar los retos enunciados anteriormente construir comunidad, confianza, empoderamiento y proyectos colectivos-es a través de la construcción de lo público. Sólo que el Estado se hace a través de las políticas públicas y de los proyectos, estrategias y acciones que emanan de ellas, y la función de las Juntas no sería, como en el pasado, la suplantación del Estado, sino la producción colectiva de reglas de juego, la participación en las decisiones sobre el presente y futuro no sólo de sí mismas, sino del desarrollo del territorio y sus habitantes. Es decir que el rol más importante de de la Junta Comunal es convertirse hoy en co-partícipe del desarrollo social y humano y del desarrollo territorial de su municipio.

Ahora el desafío está en comenzar a trabajar problemas, conflictos, problemáticas en lo público, y esto implica no sólo gestionar procesos en una escala, sino en varias, y por medio de la interlocución con otros. La participación entonces sería política por parte de unos ciudadanos, como las Juntas, que tendrían la capacidad de trabajar colectivamente y de reflexionar y actuar frente a los programas, proyectos, estrategias, contenidos, propósitos, dificultades y bondades de la esfera pública.

En el municipio de Agua de Dios, los dignatarios de algunas Juntas Comunales se dieron a la tarea de construir proyectos conjuntos que beneficiaran a cada una de estas organizaciones, pero que a la vez, contribuyeran a la calidad de vida y al desarrollo municipal y regional. 
Para lograr este propósito, estos directivos comunales tuvieron que involucrarse en la planeación participativa del desarrollo. Esta es una estrategia de construcción del desarrollo desde la base. Lo primero que se hizo fue reflexionar colectivamente sobre "el objeto" del desarrollo; o sea, sobre los proyectos que contribuirían a la construcción de lo público. Y aquí hubo un problema: definir qué era más importante para un proyecto de desarrollo, si las estrategias, las actividades o los objetivos. En general todos estos elementos son claves para el desarrollo, pero para un proyecto de esta índole tal vez lo ideal sea elaborar conjuntamente objetivos de desarrollo, que incluyan estrategias, actividades y también actores sociales para llevarlos a cabo.

Las Juntas han aprendido a desarrollar innumerables actividades que benefician a sus comunidades, incluso a echar a andar estrategias de diversa índole, pero en muy pocas ocasiones generan objetivos de trabajo, y menos en un plano como el público. Todas las actividades que hacen las Juntas no buscan otra cosa que "solucionar problemas". La mejor Junta es aquella que es capaz de solucionar el mayor número de problemas, utilizando para ello cualquier actividad que sea necesaria. Como ya se dijo, pocas veces las Juntas han construido proyectos colectivos, pero si buscamos que el capital social se reconstruya, los directivos y afiliados de las Juntas deben adquirir otros aprendizajes en este sentido.

Los elementos de un proyecto colectivo de desarrollo son esos cuatro ya anotados. El objetivo es el dispositivo que identifica la finalidad de un proyecto. Usualmente responde a las preguntas "qué" y "para qué". Las estrategias son los principios y rutas fundamentales que orientarán un proceso. Las actividades están constituidas por el conjunto de acciones que se llevan a cabo para cumplir los objetivos propuestos. Y los actores o las redes, son aquellos que pueden participar en la gestión del proyecto. Son los involucrados o interesados en el desarrollo del proyecto. Todos éstos se hacen coresponsables de la ejecución, fiscalización, y demás formas de participación de un proyecto público. Lo anterior no implica que se sustituya el papel de las administraciones municipales, departamentales y nacionales, sino que la responsabilidad frente al desarrollo sea de todos.

Construir un proyecto colectivo significó para los directivos comunales o aspirantes a serlo, la posibilidad de realizar nuevas lecturas sobre su propia realidad, unas lecturas más complejas. Este proceso de participación comunal no se queda únicamente en la formulación del proyecto colectivo para el desarrollo, sino que en él se deben asumir nuevos roles, como el de veedores de la gestión pública, gestores de política pública, co-partícipes en la puesta en marcha de los proyectos, y ciudadanos con capacidad de deliberar sobre las diferentes realidades y construir caminos para su viabilidad.

La planeación colectiva del desarrollo debe ser posible a través de procesos de participación para que sea legítima. Es decir, los comunales y el resto de actores sociales de un municipio pueden y deben hacer parte de las fases de un proyecto de esta naturaleza, tales como: a) identificación, caracterización y re-definición de las problemáticas o conflictos municipales; b) identificación de responsabilidades y de los ámbitos de gestión (micro, meso, macro); c) definición de las etapas de la gestión y de los involucrados en éstas (plan de trabajo); d) gestión (ejecución del plan de trabajo); y e) evaluación de la gestión.

Como vemos, aquí la participación tiene apellido: participación en lo público. El centro de esta propuesta no es la participación sino la construcción de lo público, 


\section{Desarrollo}

pero para hacerlo posible es indispensable que la gente se articule participando.

\section{Los problemas y los conflictos, las problemáticas y los conflictos territoriales}

Las Juntas Comunales siempre han actuado en la escala micro. Las Juntas nacieron y se desarrollaron abordando los problemas de las comunidades a las que pertenecen. El ámbito de acción es un barrio o una porción de vereda. Es un espacio micro donde conviven unos individuos. Allí, en ese territorio, es donde las Juntas encuentran su razón de existir.

Cuando hablamos de lo micro, estamos hablando de una de las escalas. Monmonier dice que la escala es "la relación entre la distancia entre el mapa y la correspondiente distancia en el terreno" ${ }^{3}$. La escala de trabajo de las Juntas es la más pequeña si se mira desde arriba con un mapa de la ciudad, por ejemplo, pero puede ser muy grande si se actúa dentro de ella. En todas las escalas hay un problema de representación y de orientación. Algunos privilegian la representación y otros la orientación. Los comunales manejan muy bien su escala, saben cómo orientarse y reconocen con alguna facilidad las representaciones sociales del territorio.

En esta escala coexisten dos elementos que son abordados por las Juntas cotidianamente: los problemas y los conflictos. Un problema es una situación, de orden individual o de orden colectivo, que representa dificultad u obstáculo para los sujetos. Aquí la responsabilidad es individual. El conflicto, en cambio, es una situación en la que se presenta una contradicción y oposición de

${ }^{3}$ Citado en DE SOUSA SANTOS, Boaventura, Estado, Derecho y

Luchas Sociales, Bogotá, ILSA, 1991, pág. 217. intereses, objetivos o valores donde las partes pueden verse afectadas por soluciones insatisfactorias. Aquí la responsabilidad es colectiva.

Las Juntas han aprendido a "solucionar" problemas a lo largo de la historia. Algunos de éstos provienen de la ausencia del Estado y otros son propios de la vida cotidiana. Los problemas son de diverso tipo, como la contaminación sonora que produce un bar en las áreas vecinas, la falta de pavimentación de una cuadra o sector territorial, etc. Las Juntas por mucho tiempo han logrado "solucionar" esos problemas gracias a su capacidad de gestión en el desorden. Hoy esa capacidad, como ya lo vimos, se ha deteriorado.

Los comunales, a su vez, se han visto envueltos en múltiples conflictos. Los conflictos siempre existirán porque hacen parte de la vida colectiva; sin embargo, de su manejo o gestión depende el provecho de los mismos. En ocasiones los directivos comunales han buscado la "solución" de los conflictos, pero los resultados han sido subóptimos para las partes. Es decir, esas "soluciones" han generado exclusiones, han exacerbado las posiciones, los opositores se han convertido en enemigos, y han generado nuevas escaladas del conflicto. La mayoría de los conflictos en los que los comunales se involucran son aquellos donde tienen que ver directamente, como las mismas discrepancias entre los miembros de la Junta, por ejemplo. Por eso para las Juntas Comunales, el resultado de esta "resolución" es la fragmentación y la desconfianza.

Los problemas y los conflictos deben asumirse por cada individuo y por las colectividades porque es básico para el desarrollo de cada cual y de toda una sociedad. El capital social se constituye por la capacidad de los individuos de articularse para afrontar asuntos que se pueden llamar "cívicos", como los problemas y los 
conflictos que afrontan a diario las Juntas Comunales. Lo anterior indica que la convivencia y la cooperación son esenciales para el desarrollo humano. Max-Neef, Elizalde y Hopenhayn sostenían al respecto del desarrollo a escala humana: "Integrar la realización armónica de necesidades humanas en el proceso de desarrollo significa la oportunidad de que las personas puedan vivir ese desarrollo desde sus comienzos, dando origen así a un desarrollo sano, autodependiente y participativo, capaz de crear los fundamentos para un orden en el que se pueda conciliar el crecimiento económico, la solidaridad social y el crecimiento de las personas y de toda la persona"4.

Dos de las grandes necesidades humanas son contar con otros y convivir con ellos. Son necesidades que deben satisfacerse. No sólo los habitantes de Girardoty Agua de Dios deben aprender a cooperar y a convivir, sino el país entero. La cooperación es básica para que los individuos interactúen y construyan bienes públicos, y la convivencia es necesaria para la vida en sociedad. Si una sociedad aprende a cooperar y a gestionar sus conflictos de manera óptima, el crecimiento personal será inmenso y el de la sociedad será incalculable. El enfoque del desarrollo a escala humana es más notorio y significativo si se activa y fortalece la escala micro, la escala natural de acción de las Juntas Comunales.

En los municipios colombianos hay otra escala de acción y reflexión: se trata de la macro. En esta escala se encuentran las problemáticas y los conflictos territoriales. Una problemática es la sumatoria de diversos problemas, se ubica en las escalas meso o

${ }^{4}$ MAX-NEEF, M., ELIZALDE, A., HOPENHAYN, M., Desarrollo a Escala Humana. Una opción para el futuro, Medellín, CEPAUR, Fundación Dag Hammarskjold, 2000, pág. 62. macro. La responsabilidad de resolverlas o abordarlas suele ser asignada o asumida por las administraciones municipales. Le apunta a una mirada disciplinar 0 fragmentada del desarrollo. Los conflictos territoriales son ante todo un proceso co-construido por los diferentes sectores y actores sociales, que le apuntarían a una visión integradora del desarrollo, donde la responsabilidad debe ser compartida (estado - sociedad). Tiene lugar en las escalas meso o macro del territorio.

Esta es una escala que ha sido colonizada por lo que se conoce como "la clase política". En esta escala es donde se produce, por ejemplo, la política pública, donde se establecen las prioridades del desarrollo, donde se planea, en términos presupuéstales, el presente y futuro de una región. Los comunales nunca han despreciado esta escala, de hecho muchas veces han querido hacer parte de esa "clase política", y han hablado con miembros de esa "clase" para lograr sus propósitos, pero no manejan bien esta escala porque no saben cómo orientarse y no comprenden sus representaciones.

Además, cambiar de escala es cambiar la realidad, es crear el fenómeno. "El poder, decía Boaventura de Sousa Santos, tiende a representar la realidad social y física en una escala escogida por su capacidad para crear los fenómenos que maximizan las condiciones de reproducción del poder. La representación/distorsión de la realidad es un presupuesto del ejercicio del poder" ${ }^{\prime \prime}$. Es decir que los comunales han aprendido a crear sus propios fenómenos y a reconocer sus realidades en su escala, pero al ingresar a una escala mayor, esos fenómenos y esas realidades se transforman en unos nuevos contextos. Las realidades son distintas por las mismas características de la escala y por los ejercicios de poder que hay en ella.

${ }^{5}$ DE SOUSA SANTOS, Boaventura, ob. cit., pág. 218. 


\section{Desarrollo}

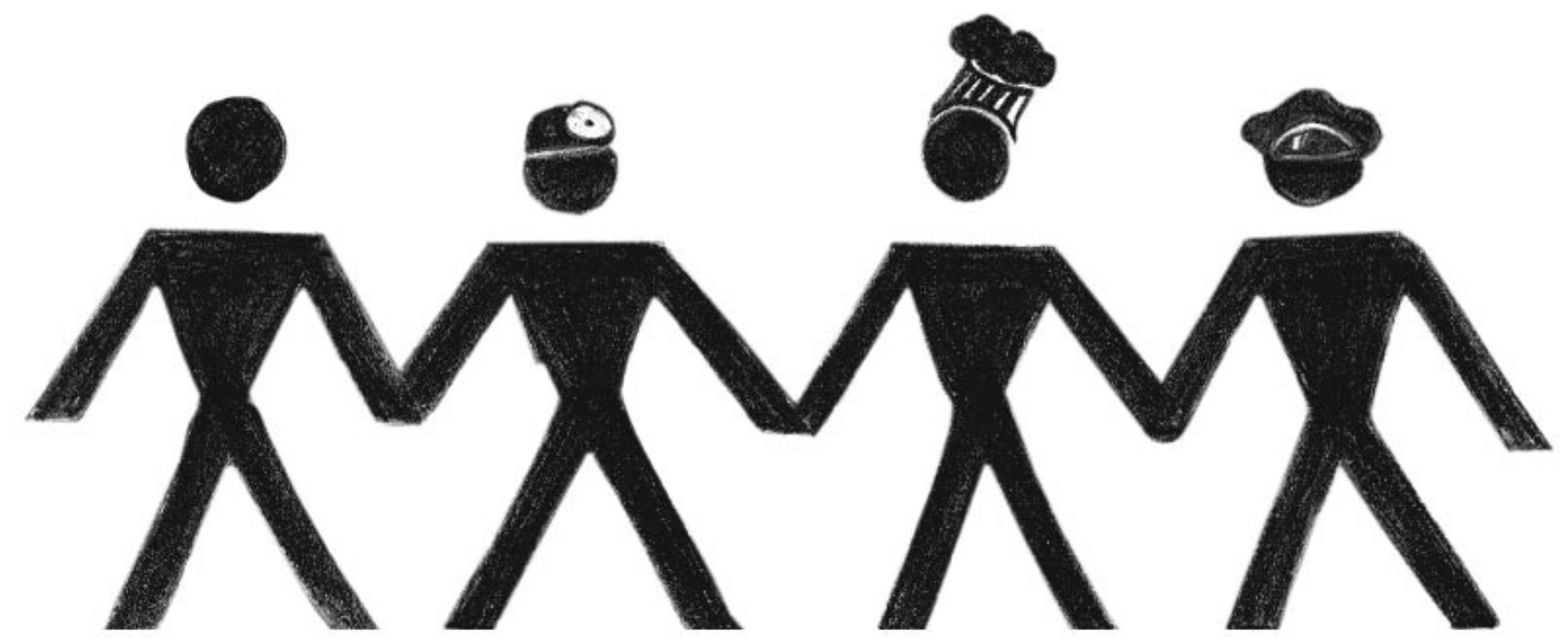

Las habilidades, destrezas, conocimientos y aprendizajes de los comunales debieran ponerse en juego en esta escala, pero, sin duda, es imprescindible adquirir otras competencias. La primera es precisamente la capacidad de leer los fenómenos desde una óptica más compleja, o si se quiere, desde una perspectiva relacional. Las problemáticas, por ejemplo, no son iguales a los problemas, pero sí los incluyen. La lectura compleja y relacional de la realidad no es dejar de ver lo pequeño, sino verlo con otros lentes, unos que lo ubiquen en un contexto espacio - temporal específico, y en la esfera de lo público.

La segunda competencia tiene que ver con la capacidad de decidir en la esfera pública. La participación en esta esfera, como ya vimos, puede ser de múltiples tipos, pero debe tener como norte la búsqueda de una mejor calidad de vida para todos los habitantes de un municipio, y la mejor manera de

lograrlo es por medio de la deliberación. Elster decía al respecto: "El simple hecho de que una asamblea de individuos defina su tarea como deliberación, en lugar de la mera negociación basada en la fuerza, ejerce una profunda influencia sobre las propuestas y argumentos que puedan efectuarse" 6 . Aprender a deliberar es aprender a argumentar y a decidir con otros sobre el presente y futuro de una región.

Asumir estas dos competencias implica para los comunales, como para cualquier otro actor social que participe en esta escala, una transformación en la cultura política; pero a su vez, para aquellos individuos que en apariencia son más conocedores de las dinámicas de esta escala, también significará un cambio en la manera y en el sentido como se produce lo público.

${ }^{6}$ ELSTER, Jon (compilador), La democracia deliberativa, Barcelona, Gedisa, 2001, pág. 133. 
Ahora, empoderarse de esta escala es asumir una postura frente al desarrollo. Primero, es la posibilidad de la libertad de construir colectivamente el territorio. Amartya Sen hablando del desarrollo como libertad, decía: "En este enfoque los individuos han de verse como seres que participan activamente -si se les da la oportunidad-en la configuración de su propio destino, no como meros receptores pasivos de los frutos de ingeniosos programas de desarrollo. El Estado y la sociedad tienen un gran papel que desempeñar en el reforzamiento y en la salvaguardia de las capacidades humanas"7.

Segundo, el abordaje de las problemáticas es una de las grandes prioridades del desarrollo sostenible y sustentable. Lo importante para estas perspectivas de desarrollo, no es tanto trabajar las problemáticas que las administraciones suponen son de mayor relevancia -como se hace hoy en los planes de desarrollo-, sino asumir las problemáticas desde la óptica de la contribución a un ambiente físico y simbólico que redunde en la mejor calidad de vida.

Y tercero, si asumimos lo que hemos llamado "conflictos territoriales", estaríamos adentrándonos en lo que Sergio Boisier ha llamado el desarrollo o capital sinergético. Estos "conflictos" no son más que la manera de asumir las diferentes realidades que se perciben en esta escala, pero de una forma completa, articulada y sinérgica. Los llamamos conflictos porque ésta es una forma de leer y actuar en un contexto. Los conflictos pueden dinamizar una sociedad, todo depende de cómo se asuman. El capital sinergético es, según Boisier, "la capacidad social 0 , mejor, la capacidad societal de promover acciones en conjunto dirigidas a fines colectiva y democráticamente aceptados, con el conocido resultado de obtenerse así un producto final que

${ }^{7}$ SEN, Amartya, "Los fines y los medios del desarrollo", en: El desarrollo como libertad, Editorial Planeta, 1999, pág 75. es mayor que la suma de los componentes"8. La idea de Boisier es que el desarrollo territorial se logre construyendo sinergias entre diversos capitales, como el económico, el cognitivo, el simbólico, el cultural -siguiendo a Bourdieu-, el institucional, el psicosocial, el capital social, el cívico -partiendo de lo dicho por Putnam- y el humano.

El desarrollo no puede fragmentarse, debe estar concatenado. El desarrollo aquí es sinergia, es articulación de todos estos capitales tangibles, pero especialmente de los intangibles. Por eso tal vez el papel más significativo de los comunales en esta escala es el de servir de puente para que esos capitales sean reconocidos, deliberados y producidos sinérgicamente en el desarrollo del territorio.

Lo que prima aquí es reconocer la importancia de la gestión en las escalas del desarrollo. La escala micro es fundamental para la potenciación del desarrollo humano. Los aprendizajes más significativos, retomando a Ausubel, se generan en el ambiente más inmediato, más próximo. La macro, en cambio, es un espacio en el que puede ser más decisiva la libertad de los sujetos de autodeterminar su destino, el lugar desde el cual es más viable producir sinergias en el desarrollo, y desde donde se pueden potenciar proyectos y procesos que gestionen los conflictos del territorio.

Las escalas del desarrollo son niveles de actuación y de reflexión dentro de un mapa territorial. Los mapas y las escalas necesitan no sólo diseñarse, sino vivirse desde la perspectiva del desarrollo y en el marco de la esfera pública.

\footnotetext{
${ }^{8}$ Cita del texto titulado "El desarrollo territorial a partir de la construcción del capital sinergético", que se encuentra en: http:// www.redelaldia.org/IMG/pdf/1122.pdf.
} 


\section{Las redes comunicativas como herramienta para la construcción de lo público}

Queda una última pregunta: ¿cómo se produce esta reflexión - acción en las dos escalas del desarrollo? Ya habíamos dicho que para conocer y renovar la escala macro existe la necesidad de transformar la cultura política de los ciudadanos, de desarrollar dos competencias: la capacidad de decidir a través de la deliberación y la lectura compleja y relacional de las realidades. Y a su vez, transitar por la escala micro, fortaleciendo el desarrollo de las capacidades humanas, especialmente en la convivencia y la cooperación.

Lo anterior no es posible sin que los actores sociales se comuniquen. Comunicarse no es únicamente una cuestión de poner en común, en un proyecto de desarrollo comunicar es construir sentidos y significaciones colectivas que produzcan lo público, por medio del robustecimiento de las acciones colectivas. La comunicación no es tampoco el intercambio de información de una fuente a otra ni su retroalimentación, la comunicación es un proceso intersubjetivo de generación de relaciones en dos planos: en el humano, en la posibilidad de auto organizarse para hacer posible las expectativas individuales y colectivas, y en el plano territorial, en la mediación de las sinergias entre los distintos capitales presentes en un contexto local, municipal, regional o nacional.

Lo que proponemos entonces es la generación de redes comunicativas para la acción colectiva. Lo que buscamos en Agua de Dios y Girardot es que estas redes se conviertan en los escenarios en los cuales se presenta el juego comunicativo. Un escenario en el que se comparten lenguajes comunes o no comunes, simbolizaciones, lógicas, subjetividades y racionalidades. Las redes comunicativas serían el

\section{Desarrollo}

espacio de construcción de marcos de interpretación sobre lo social. En ellas tendrían cabida las organizaciones sociales, como las Juntas Comunales, y otros actores sociales o institucionales.

De lo que hablamos es de una interrelación que se produce en el plano de lo público y que parte de los intereses particulares para llegar a los públicos. Y en estas redes caben diferentes escenarios de significación -mediáticos e interpersonales- que se implementarán en la medida que lo requieran los procesos construidos.

Cuando hablamos de una red comunicativa para el desarrollo estamos apostándole a varios propósitos:

El primero de ellos es la construcción de sinergias entre los miembros de la red. Eric Sommer define sinergia como "un sistema de interacciones entre dos o más actores o centros de acción"9. La sinergia surge cuando dos seres interactúan o trabajan juntos de cualquier manera y de cualquier razón. La producción de sinergia social es una producción compleja. En un territorio cualquiera los sujetos sociales son diversos, y no sólo por su cultura o culturas, sino especialmente por sus intereses y expectativas.

En estricto sentido, la sinergia es una acción combinada de dos o más agentes, resultando mayor ésta que la suma de las acciones individuales de cada uno de ellos. Esto implica que la acción colectiva emprendida por varios actores sociales debe ser más significativa para cada uno de ellos, que su propia acción egoísta. Las sinergias se alcanzan, entonces, construyendo puentes entre las macromotivaciones -del desarrollo

${ }^{9}$ La frase de Sommer es citada por BOISIER, Sergio, “ ¿Y si el desarrollo fuese una emergencia sistémica?", publicado en la revista del CLAD Reforma y Democracia, №. 27, Caracas, octubre de 2003, pág. 7. El texto fue consultado el 5 de mayo de 2008 en: http://www. yorku.ca/ishd/CUBA.LIBRO.06/DEL/CAPITULO3.pdf 


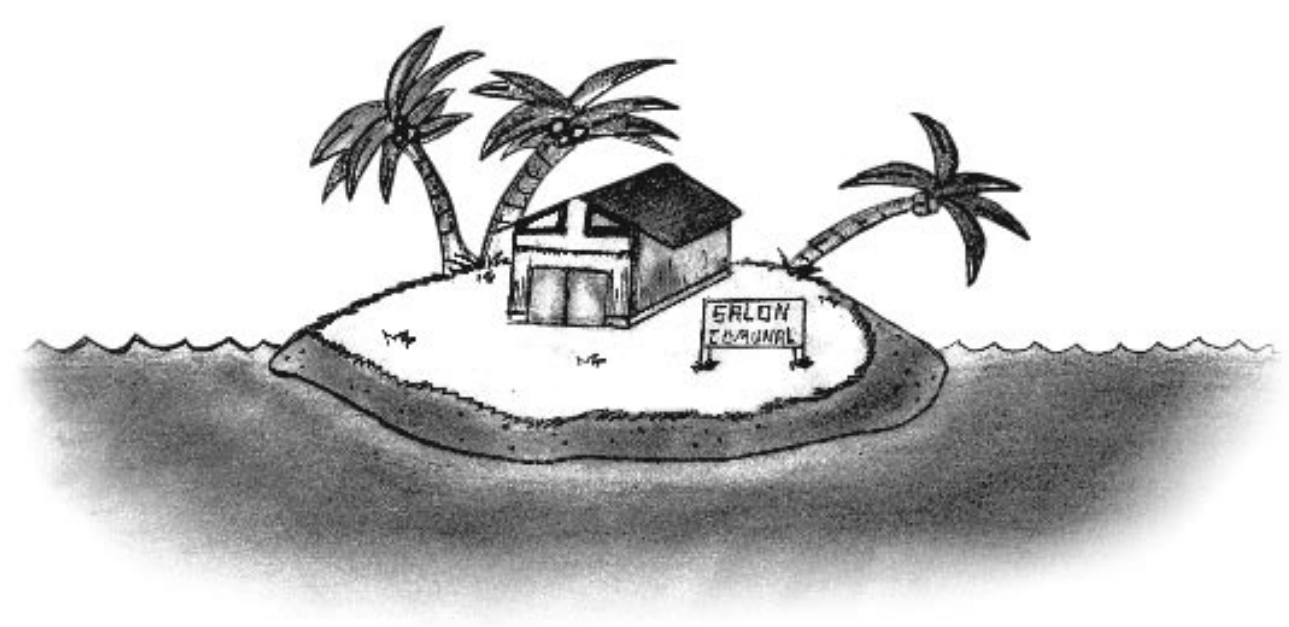

regional, por ejemplo- con las micromotivaciones del desarrollo humano.

Las sinergias también se alcanzan por medio de la cooperación y de la confianza. Estos dos elementos clave del capital social se producen en la interacción y en la relación. La interacción es un proceso de construcción de significados compartidos, y gracias a ese proceso existe una relación. De igual modo, la relación es un proceso dinámico que es co-construido por las partes. La cooperación se obtiene gracias a una relación de confianza generada entre varios y a unas interacciones en las que los valores como la participación, la reciprocidad y el apoyo mutuo se convierten en significados compartidos. La confianza se adquiere en las relaciones en las que prima la sinceridad, la lealtad, la libertad y la autonomía, y a unas interacciones en las que se expresa la cooperación, la acción colectiva común no sólo presente sino futura, y la necesidad del "otro" para la construcción de un "yo" y de un "nosotros".

El segundo propósito tiene que ver con la articulación de los diferentes factores que pueden incidir en el desarrollo del territorio. Boisier asegura que el desarrollo depende de la interacción: "de la conectividad y de la interactividad entre varios (muchos) factores de menor escala (de escala "local" en el lenguaje de la complejidad, por ejemplo, de una cultura, de relaciones de confianza, del papel de las instituciones, de la justicia, de la libertad, del conocimiento socializado en una comunidad, del conocimiento y de las destrezas "incrustadas" en las personas, de la salud, de los sentimientos, de los sentimientos y las emociones que acotan una supuesta racionalidad instrumental, de la autoconfianza, de elementos simbólicos que constituyen formas de poder, etc.."

Es decir, de lo que se trata es de asumir la red como un espacio en el que se generen las relaciones necesarias en el marco de un sistema de desarrollo. Todos los elementos descritos son claves en el desarrollo, de hecho ninguno de ellos es menos importante que el otro o los otros. Cada uno debe activarse de manera simultánea para que la calidad de vida mejore y sea más equitativa. La red comunicativa es precisamente el lugar donde diversos

${ }^{10} \mathrm{lbíd}$., pág. 8. 
actores u organizaciones construyen conocimiento sobre el territorio complejizándolo, es decir, relacionándolo entre sí, ampliándolo (en términos simbólicos y relacionales) y diversificándolo cada vez más.

La tercera función de la red comunicativa es la interlocución entre las escalas del desarrollo. Sin duda varios de los elementos que podemos enunciar como funciones de la red, tales como ampliar la malla de conexiones, incrementar el flujo interactivo, favorecer la información entre los miembros de la red y aumentar los procesos colectivos, no tendrían mucha pertinencia en la vida de muchos actores sociales, como las Juntas Comunales, si no asumimos que existen escalas 0 lecturas y acciones sobre el desarrollo.

El juego del desarrollo no se hace en un solo escenario. El desarrollo se produce en distintos escenarios de significación, que hemos llamado aquí escalas. Como ya vimos, las escalas tienen sus propias "realidades" que son tangibles. En la red pueden participar actores de diversa índole y procedencia, por ejemplo, organizaciones sociales como las Juntas Comunales, pero también gremios, partidos políticos, etc., es decir, actores o agentes que se desenvuelven mejor en una u otra escala. La red se puede convertir en el espacio en que todos estos actores comprendan la necesidad de validar los saberes sociales, provengan de una escala o de otra, e interlocutar entre todos.

Y la cuarta función de la red comunicativa es la generación de un tejido social para construir un desarrollo humano, social y sinergético. Es decir, la red es el espacio en que los actores sociales, a partir de una dinámica de interacciones, relaciones e interrelaciones, se convierten en sujetos o agentes del desarrollo municipal, regional, nacional o internacional. Este es un proceso comunicativo que debe comenzar

\section{Desarrollo}

desde el presente -tal como se inició en Agua de Dios y Girardot- para que el mañana se produzca y no sólo exista, y para que el desarrollo se genere desde abajo, desde los intereses, necesidades y expectativas de diversos sectores que tradicionalmente no han sido tenidos en cuenta.

Si logramos crear capital social a través de la constitución de redes comunicativas, estaremos construyendo presente y futuro para los habitantes de esta región, dado que en la interlocución producida se alcanza la apropiación territorial y la participación en las decisiones sobre el territorio; así mismo, este proceso asociativo, que estaría animado y acompañado por las instituciones estatales de los municipios, las provincias y el departamento de Cundinamarca, produciría equidades sociales y políticas, tal como se persigue en los objetivos del milenio. 13 


\section{Medicariomes}

\section{Bibliografía}

BOISIER, Sergio, "¿Y si el desarrollo fuese una emergencia sistémica?", en: Revista del CLAD Reforma y Democracia, No. 27, Caracas, octubre de 2003. Consultado el 5 de mayo de 2008 en http://www.yorku.ca/ishd/CUBA. LIBRO.06/DEL/CAPITULO3.pdf

DE SOUSA SANTOS, Boaventura, Estado, Derecho y Luchas Sociales, Bogotá, ILSA, 1991.

ELSTER, Jon (compilador), La democracia deliberativa, Barcelona, Gedisa, 2001.

ESPASA, Calpe, Gran Enciclopedia Espasa, No 15, Colombia, 2005.

MAX-NEEF, M., ELIZALDE, A., HOPENHAYN, M., Desarrollo a Escala Humana. Una opción para el futuro, Medellín, CEPAUR, Fundación Dag Hammarskjold, 2000.

SEN, Amartya, "Los fines y los medios del desarrollo", en: El desarrollo como libertad, Editorial Planeta, 1999.

VELÁSQUEZ, Fabio y GONZÁLEZ, Esperanza, ¿Qué ha pasado con la participación ciudadana en Colombia?, Bogotá, Fundación Corona, Fundación Social, Foro Nacional por Colombia, Banco Mundial, CIDER, Universidad de Los Andes, Corporación Región, Corporación Viva La Ciudadanía, Corporación Transparencia por Colombia, 2003. 